\title{
Comparison of Genetic and Virulence Diversity of Melampsora larici-populina Populations on Wild and Cultivated Poplar and Influence of the Alternate Host
}

\author{
Pierre R. Gérard, Claude Husson, Jean Pinon, and Pascal Frey
}

Institut National de la Recherche Agronomique (INRA), Equipe de Pathologie Forestière, UMR 1136 Interactions Arbres—Microorganismes, IFR 110, 54280 Champenoux, France.

Current address of P. R. Gérard: Laboratoire Ecologie, Systématique et Evolution, UMR ENGREF-CNRS 8079, Bâtiment 360, Université

Paris Sud, 91405 Orsay Cedex, France.

Accepted for publication 4 May 2006.

\begin{abstract}
Gérard, P. R., Husson, C., Pinon, J., and Frey, P. 2006. Comparison of genetic and virulence diversity of Melampsora larici-populina populations on wild and cultivated poplar and influence of the alternate host. Phytopathology 96:1027-1036.

The aims of this study were, first, to compare the genetic and virulence diversity between populations of the rust fungus Melampsora larici-populina on wild and cultivated poplar stands and, second, to investigate the influence of the presence of the alternate host of the pathogen, larch, on which its sexual reproduction occurs, on these diversities. Nine French M. larici-populina populations collected from poplar trees in autumn and

typic structure clearly distinguished the cultivated stands with high richness and complexity from the wild stands with low richness and complexity. High linkage disequilibria between virulences indicated preferential virulence associations, probably due to selection by the host. In all, 19 random amplified polymorphic DNA (RAPD) markers were used, which revealed a very high genetic diversity in the 743 isolates analyzed. The nine populations from poplar appeared moderately differentiated, indicating long-distance gene flow, and no isolation by distance was found. Linkage disequilibria between RAPD markers generally were low, indicating frequent recombination, but they were not lower in populations located near larch, probably due to long-distance dispersal.
\end{abstract} four populations collected from larch trees during the following spring were analyzed using both virulence factors and neutral markers. In all, 30 pathotypes were identified within the 13 populations studied. The patho-
Additional keywords: black poplar, dominant markers, population genetics, Populus nigra, rust epidemics.
Among the major forces influencing the structure and evolution of pathogen populations, sexuality plays an important role, through the consequences of recombination $(4,27)$. In many cases, it has been shown that sexually reproducing phytopathogenic fungi populations show a higher genotypic diversity and lower linkage disequilibria (6). Many fungi have complex life cycles, alternating between sexuality on one host and asexual multiplication on another (38). The most efficient pathogens, particularly in anthropized environments, seem to be those possessing this type of periodic sexual cycle, generating genetic diversity, followed by many asexual cycles allowing the amplification of the most adapted genotypes (33). Moreover, these fittest genotypes are amplified in long-distance dispersed fungi, such as rust or mildew agents (27). Local eradication of the alternate host for the sexual life stage should have two effects if the winter survival of asexual spores is not possible. First, infections should be less frequent and arise later, because no sexual spores are produced locally and, therefore, all primary infections result from longdistance immigration of sexual spores. Second, fewer different genotypes should be represented, because these long-distance events are rare. Overall, this will lead to higher linkage disequilibria because of a more clonal nature of the populations and should decrease the evolutionary potential of the fungus on its asexual host while reducing the number of infections. Indeed, elimination of the alternate host Berberis vulgaris from the wheat

Corresponding author: P. Frey; E-mail address: frey@nancy.inra.fr

DOI: 10.1094/PHYTO-96-1027

(C) 2006 The American Phytopathological Society fields of the central Great Plains of North America led to a decrease of virulence diversity and an increase of linkage disequilibrium in populations of the wheat stem rust fungus (Puccinia graminis f. sp. tritici) (40). In North America, a higher genetic diversity was found in populations of the poplar rust fungus Melampsora medusae f. sp. deltoidae in areas of sympatry between poplar and larch, the alternate host, compared with areas of allopatry with larch, where a loss of alleles during migration was observed (3). The pattern was less clear in the case of the willow rust fungus, $M$. larici-epitea, where one population in the vicinity of the alternate host (larch) had a very low genetic diversity and very high linkage disequilibria. The authors proposed several hypotheses to explain this result; for example, the winter survival of asexual spores or severe bottlenecks linked to the sexual cycle (42).

Host genetic variability and mating system also can influence the evolution of pathogen populations (13). For example, higher virulence polymorphism was found in $M$. lini populations originated from outcrossed metapopulations of Linum marginale compared with inbred host populations (8). Wild host populations are genetically much more diverse than cultivated crops and this may influence the genetic diversity of the pathogen populations. However, no clear pattern emerges to date, with either fewer pathotypes found in wild than cultivated populations (35) or no difference in structure found between the two (32). On the other hand, pathogen populations on wild versus cultivated host populations may be differentiated for neutral markers even if they share similar pathotypes because of limits to gene flow between the two types of host populations. Indeed, migration can have an important influence on the structure and evolution of pathogen 
populations, particularly in the case of long-distance dispersed pathogens (5). For instance, long-distance dispersal is a crucial parameter allowing adaptation of populations of the highly clonal wheat stripe rust agent ( $P$. striiformis f. sp. tritici) (17). When associated with the emergence of recombination, long-distance dispersal also dramatically increased genotypic diversity in European Phytophthora infestans populations (44).

Poplar is among the most intensively cultivated forest trees in Europe, and black poplar (Populus nigra), one of the parents of Euramerican hybrid cultivars (Populus $\times$ euramericana), is widespread in natural European riparian forests. Hence, the poplarrust pathosystem could provide a good example for comparing the genetic diversity of pathogen populations on wild and cultivated hosts (35). Among the forest species planted in Europe, poplar trees are particularly exposed to the attacks of many pathogens because of their intensive cultivation over several decades. Moreover, stands are even aged and monoclonal, and the number of cultivars planted in a given region is limited. The poplar leaf rust agent $M$. larici-populina, an obligate macrocyclic basidiomycete, which has its sexual stage on larch (Larix sp.) and its asexual stage on poplar, has caused extensive damage for many years. Severe economic losses have been shown to reach $50 \%$ of annual growth in 6-year-old cultivated stands through decreased photosynthesis efficiency, early defoliation, and increased susceptibility to other pests and diseases (24). Most poplar cultivars share $P$. deltoides as one of their parents, a species that did not evolve in the presence of European parasites (35) and which has been a source of disease resistance genes $(18,22)$. After several years of cultivation of completely resistant cultivars, M. larici-populina broke down several complete resistance genes, and new virulent genotypes produced by recombination were amplified by a strong selection pressure (12). Newly released complete resistance genes were increasingly rapidly overcome after each new commercial use, which prompted a search for durable resistance $(9,36)$. Even varietal mixtures of poplar clones were not able to reduce disease severity (29).

In contrast, the rust incidence on wild poplar stands, mainly composed of black poplar, appeared to be low (12). Complete resistance has not been detected so far in P. nigra (36), suggesting the presence of a partial resistance (23). A previous characteriza-

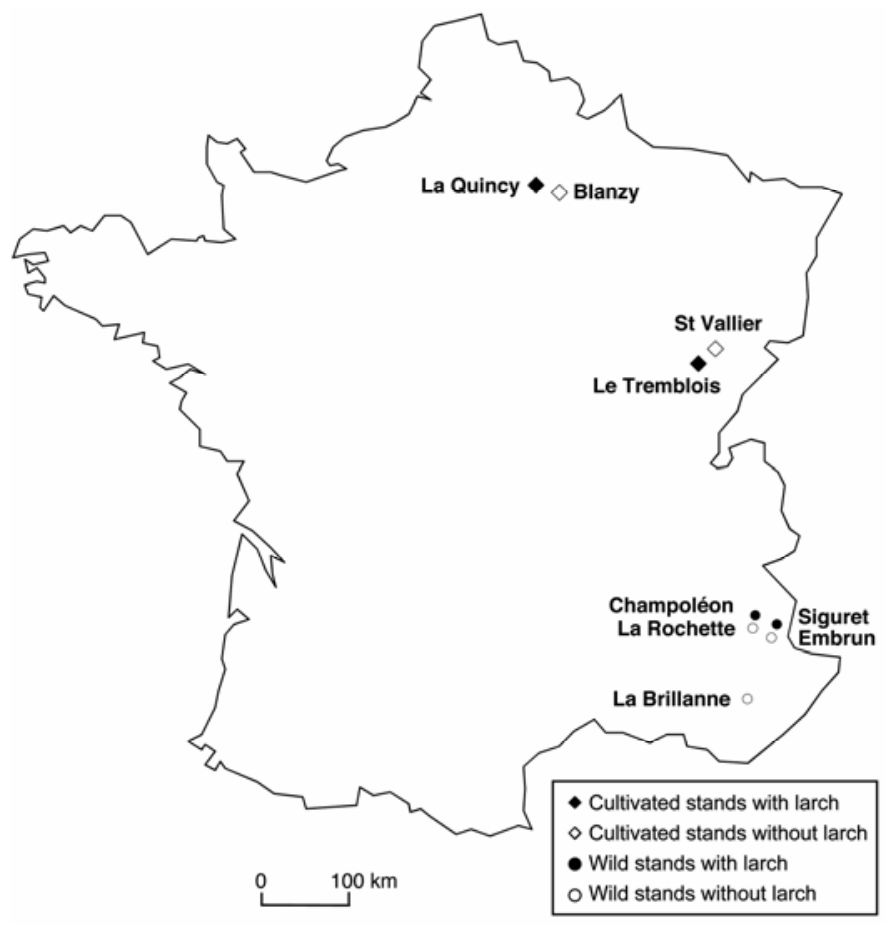

Fig. 1. Geographic location of the nine study sites in France. tion of the population structure of M. larici-populina, based only upon virulence markers, revealed high differentiation between fungal populations collected in wild versus cultivated poplar stands (35). This study showed that complex pathotypes mainly recovered from cultivated poplar stands were absent or very rare in riparian $P$. nigra populations. Furthermore, this previous study did not take into account the presence or absence of larch in the vicinity of the studied poplar stands.

The aims of the present study were to (i) compare pathogen population structure and diversity in wild and cultivated poplar stands and evaluate the extent of gene flow between them using both genetic (random amplified polymorphic DNA [RAPD]) and virulence markers and (ii) evaluate the influence of the presence of the alternate host on the population structure and diversity of M. larici-populina by comparing the pathotypic and genetic structure of populations in poplar stands with or without larch in the vicinity. If gene flow is not too high, we expect a decrease of pathotype diversity and an increase of overall linkage disequilibrium in the sites where larch is not present. Furthermore, we assessed the pathotypic structure of several populations collected from larch the following spring at the same sites. To our knowledge, this is the first study of M. larici-populina population diversity with neutral molecular markers, aimed at assessing the role of larch in natural populations.

\section{MATERIALS AND METHODS}

Sampling design. Four pairs of sites, two of cultivated poplar stands and two of wild stands, were chosen in September 2001 in France. Within each pair, one site had larch in its immediate vicinity (less than $200 \mathrm{~m}$ ) and the other did not (Fig. 1; Table 1). In all cases, the two sites within a pair were 10 to $20 \mathrm{~km}$ apart. The two pairs of cultivated stands were located in regions where poplar cultivation is widespread, the Saône River Valley (FrancheComté region, northeastern France) and the Aisne River Valley (Picardie region, northern France). Populations of $M$. laricipopulina were collected from plantations of Populus $\times$ euramericana 'Robusta', a cultivar susceptible to all known M. laricipopulina pathotypes, in order to avoid any selection on virulences by resistant cultivars (35). Hence, pathotype characterization was not biased by complete resistances of clones on which isolates were harvested. The two pairs of wild stands were located in Alpine valleys in southeastern France, the Drac and the Durance River Valleys. These riparian stands are composed primarily of P. nigra and are located far from major poplar cultivation zones. A ninth site was chosen downstream in the Durance River Valley (La Brillanne), far from the poplar-larch sympatry zone $(\approx 100 \mathrm{~km}$ from Siguret). Furthermore, four additional populations were sampled on larch (Larix decidua) in May 2002, in the vicinity of the four studied poplar stands (Le Tremblois, La Quincy, Siguret, and Champoléon) (Table 2).

Pathotype identification. In all, $\approx 200$ moderately infected leaves were harvested in each of the nine poplar stands in September 2001 (i.e., at the end of an epidemic). One uredinium per leaf was transferred onto leaf disks of $P . \times$ euramericana 'Robusta', to ultimately obtain $\approx 100$ isolates per population. A $10-\mu \mathrm{l}$ droplet of water agar $\left(0.1 \mathrm{~g} \mathrm{liter}^{-1}\right)$ was deposited onto each selected uredinium with a micropipette and urediniospores were dispersed within the droplet with the micropipette. The resulting spore suspension was applied as 1- $\mu$ l droplets on 12-mm-diameter leaf disks of 'Robusta'. Leaf disks were incubated floating on deionized water in 24-well polycarbonate cell culture plates, abaxial surface uppermost, at $20^{\circ} \mathrm{C}$ under continuous illumination (fluorescent light, $25 \mathrm{mmol} \mathrm{s}^{-1} \mathrm{~m}^{-2}$ ). After an incubation period of 8 to 10 days, the sporulating disks were harvested and the urediniospores were suspended in $100 \mu \mathrm{l}$ of water agar $\left(0.1 \mathrm{~g} \mathrm{liter}^{-1}\right)$. Each mono-uredinial isolate then was inoculated as 1- $\mu$ l droplets onto 12-mm-diameter leaf disks of a differential set of eight poplar 
clones and incubated as described above. This differential set allowed us to detect the presence of eight specific virulences in the pathogen (35,36): Populus $\times$ euramericana 'Ogy' (Vir1), Populus $\times$ jackii 'Aurora' (Vir2), Populus $\times$ euramericana 'Brabantica' (Vir3), Populus $\times$ interamericana 'Unal' (Vir4), Populus $\times$ interamericana 'Rap' (Vir5), P. deltoides '87B12' (Vir6), Populus $\times$ interamericana 'Beaupré' (Vir7), and Populus $\times$ interamericana 'Hoogvorst' (Vir8). The formation of uredinia on the leaf disks was checked daily between the 7th and the 14th day postinoculation, and the resulting pathotype (combination of virulences) was determined for each isolate.

The rust incidence was so low in La Rochette that only 65 isolates could be studied. The same protocol was applied to the aecidia collected from larch needles in May 2002. Only 25 and 86 isolates could be collected from larch at Champoléon and Siguret, respectively.

RAPD assays. The nine populations collected in September 2001 were analyzed using the RAPD technique first described by Williams et al. (47) and Welsh and McClelland (46). After pathotype identification, sporulating leaf disks were dried in Eppendorf tubes in a desiccator at room temperature for $24 \mathrm{~h}$, and urediniospores from each isolate were harvested by tapping the tube and removing the leaf disk. Urediniospores were kept at $-85^{\circ} \mathrm{C}$ until DNA extraction. DNA was extracted from $1 \mathrm{mg}$ of urediniospores according to the procedure described by Pei et al. (34) and modified by Samils et al. (42) using two 3 -mm-diameter and $\approx 20$ 2-mm-diameter glass beads to homogenize the urediniospores, and using the DNeasy Plant Mini Kit (Qiagen, Courtaboeuf, France) instead of the cetyltrimethylammonium bromide procedure. Six nanograms of total DNA were used as template under the polymerase chain reaction (PCR) conditions used by Feau (11), adapted from the RAPD technique. In a preliminary study aimed to assess the usefulness of 80 RAPD primers (OPE, OPF, OPG, and OPH kits; Operon Technology, Alameda, CA) for genotyping $M$. larici-populina populations, only four primers were found to be useful and reproducible in the PCR conditions tested (11). Three of these four RAPD primers were chosen for this study: OPF-14, OPG-11, and OPG-15 (Operon Technology). Bands obtained were visualized with ethidium bromide and digitized with the Gel Doc 2000 gel documentation system (Bio-Rad, Marnes-la-Coquette, France). To ensure the reproducibility of RAPD markers, the experiments were repeated once and only bands that showed the same patterns among both amplifications were retained.

Data analyses. Structure and diversity of M. larici-populina populations were described using several variables: frequency of virulences and pathotypes, pathotype diversity (or richness), and complexity (mean number of virulences in pathotypes) (35). Indices of ecological diversity (26) often are used for characterizing pathogen populations, particularly in the case of cereal

TABLE 1. Characteristics of the collection sites

\begin{tabular}{|c|c|c|c|c|c|c|c|}
\hline Locality & Region & River & Longitude & Latitude & Elevation (m) & Compartment & $\operatorname{Larch}^{\mathrm{a}}$ \\
\hline Blanzy & Picardie & Aisne & $3^{\circ} 40^{\prime} 45.2^{\prime \prime} \mathrm{E}$ & $49^{\circ} 19^{\prime} 52.1^{\prime \prime} \mathrm{N}$ & 107 & Cultivated & - \\
\hline La Quincy & Picardie & Aisne & $3^{\circ} 26^{\prime} 14.8^{\prime \prime} \mathrm{E}$ & $49^{\circ} 25^{\prime} 13.2^{\prime \prime} \mathrm{N}$ & 83 & Cultivated & + \\
\hline St Vallier & Franche-Comté & Saône & $5^{\circ} 40^{\prime} 24.9^{\prime \prime} \mathrm{E}$ & $47^{\circ} 27^{\prime} 56.5^{\prime \prime} \mathrm{N}$ & 210 & Cultivated & - \\
\hline Le Tremblois & Franche-Comté & Saône & $5^{\circ} 34^{\prime} 33.8^{\prime \prime} \mathrm{E}$ & $47^{\circ} 22^{\prime} 16.7^{\prime \prime} \mathrm{N}$ & 236 & Cultivated & + \\
\hline La Rochette & Alps & Drac & $6^{\circ} 08^{\prime} 45.2^{\prime \prime} \mathrm{E}$ & $44^{\circ} 36^{\prime} 01.0^{\prime \prime} \mathrm{N}$ & 1,201 & Wild & - \\
\hline Champoléon & Alps & Drac & $6^{\circ} 15^{\prime} 52.0^{\prime \prime} \mathrm{E}$ & $44^{\circ} 41^{\prime} 29.1^{\prime \prime} \mathrm{N}$ & 1,188 & Wild & + \\
\hline Embrun & Alps & Durance & $6^{\circ} 30^{\prime} 42.2^{\prime \prime} \mathrm{E}$ & $44^{\circ} 33^{\prime} 36.9^{\prime \prime} \mathrm{N}$ & 802 & Wild & - \\
\hline Siguret & Alps & Durance & $6^{\circ} 33^{\prime} 41.3^{\prime \prime} \mathrm{E}$ & $44^{\circ} 37^{\prime} 33.4^{\prime \prime} \mathrm{N}$ & 935 & Wild & + \\
\hline La Brillanne & Alps & Durance & $5^{\circ} 54^{\prime} 07.9^{\prime \prime} \mathrm{E}$ & $43^{\circ} 56^{\prime} 01.2^{\prime \prime} \mathrm{N}$ & 350 & Wild & - \\
\hline
\end{tabular}

a Presence $(+)$ or absence $(-)$ of larch in the vicinity of the poplar stands.

TABLE 2. Pathotypic and genotypic characterization of the populations of Melampsora larici-populina ${ }^{\mathrm{a}}$

\begin{tabular}{|c|c|c|c|c|c|c|c|c|c|c|c|c|c|c|c|}
\hline \multirow[b]{2}{*}{ Locality } & \multirow[b]{2}{*}{ Comp. $^{\text {b }}$} & \multirow[b]{2}{*}{$\operatorname{Larch}^{\mathrm{c}}$} & \multirow[b]{2}{*}{$\operatorname{Host}^{\mathrm{d}}$} & \multirow[b]{2}{*}{ Date } & \multicolumn{6}{|c|}{ Virulence markers } & \multicolumn{5}{|c|}{ RAPD markers } \\
\hline & & & & & $N_{i}^{\mathrm{e}}$ & $N_{p}^{\mathrm{f}}$ & $\mathrm{H}_{\mathrm{SR}^{\mathrm{g}}}^{\mathrm{g}}$ & $C_{i}^{\mathrm{h}}$ & LD pop. $(\%)^{\mathrm{i}}$ & LD path. $(\%)^{\mathrm{j}}$ & $N_{i}^{\mathrm{e}}$ & $N_{G}{ }^{\mathrm{k}}$ & $\mathrm{H}_{\mathrm{SR}^{\mathrm{g}}}^{\mathrm{g}}$ & $\mathrm{H}^{\mathrm{l}}$ & $\operatorname{LD}(\%)^{\mathrm{m}}$ \\
\hline Blanzy & $\mathrm{C}$ & - & $\mathrm{P}$ & September 2001 & 103 & 12 & 0.38 & 3.34 & $20(3 / 15)$ & $0(0 / 15)$ & 97 & 89 & 0.98 & 0.38 & 2.7 \\
\hline La Quincy & $\mathrm{C}$ & + & $\mathrm{P}$ & September 2001 & 105 & 12 & 0.36 & 3.95 & $14(3 / 21)$ & $0(0 / 21)$ & 97 & 91 & 0.98 & 0.39 & 4.0 \\
\hline La Quincy & $\mathrm{C}$ & + & $\mathrm{L}$ & May 2002 & 110 & 15 & 0.39 & 4.00 & $14(4 / 28)$ & $0(0 / 28)$ & ND & ND & ND & ND & ND \\
\hline St Vallier & $\mathrm{C}$ & - & $\mathrm{P}$ & September 2001 & 99 & 13 & 0.39 & 2.82 & $24(5 / 21)$ & $0(0 / 21)$ & 86 & 76 & 0.96 & 0.32 & 1.5 \\
\hline Le Tremblois & $\mathrm{C}$ & + & $\mathrm{P}$ & September 2001 & 106 & 18 & 0.45 & 3.51 & $48(10 / 21)$ & $5(1 / 21)$ & 93 & 76 & 0.93 & 0.34 & 0.7 \\
\hline Le Tremblois & $\mathrm{C}$ & + & $\mathrm{L}$ & May 2002 & 113 & 18 & 0.46 & 3.49 & $38(8 / 21)$ & $0(0 / 21)$ & ND & ND & ND & ND & ND \\
\hline La Rochette & W & - & $\mathrm{P}$ & September 2001 & 65 & 6 & 0.27 & 1.60 & $67(10 / 15)$ & $0(0 / 15)$ & 51 & 42 & 0.92 & 0.33 & 2.9 \\
\hline Champoléon & W & + & $\mathrm{P}$ & September 2001 & 101 & 8 & 0.23 & 0.45 & $27(4 / 15)$ & $0(0 / 15)$ & 60 & 53 & 0.96 & 0.35 & 2.9 \\
\hline Champoléon & $\mathrm{W}$ & + & $\mathrm{L}$ & May 2002 & 25 & 4 & 0.27 & 0.40 & $0(0 / 3)$ & $0(0 / 3)$ & ND & ND & ND & ND & ND \\
\hline Embrun & $\mathrm{W}$ & - & $\mathrm{P}$ & September 2001 & 100 & 3 & 0.18 & 0.31 & $0(0 / 1)$ & $0(0 / 1)$ & 87 & 81 & 0.98 & 0.34 & 2.0 \\
\hline Siguret & W & + & $\mathrm{P}$ & September 2001 & 90 & 6 & 0.21 & 0.38 & $0(0 / 21)$ & $0(0 / 21)$ & 75 & 73 & 0.99 & 0.37 & 2.0 \\
\hline Siguret & $\mathrm{W}$ & + & $\mathrm{L}$ & May 2002 & 86 & 4 & 0.20 & 0.67 & $0(0 / 3)$ & $0(0 / 3)$ & ND & ND & ND & ND & ND \\
\hline La Brillanne & $\mathrm{W}$ & - & $\mathrm{P}$ & September 2001 & 104 & 2 & 0.09 & 0.15 & ND & ND & 91 & 55 & 0.81 & 0.29 & 3.7 \\
\hline
\end{tabular}

${ }^{a}$ RAPD = random amplified polymorphic DNA, LD = linkage disequilibria, and ND = not determined.

b Compartment: $\mathrm{C}=$ cultivated and $\mathrm{W}=$ wild.

c Presence (+) or absence (-) of larch in the vicinity of the poplar stands.

${ }^{\mathrm{d}}$ Host on which populations were harvested: $\mathrm{P}=$ poplar and $\mathrm{L}=$ larch.

e $N_{i}=$ number of isolates analyzed with virulence or RAPD markers.

f $N_{p}=$ number of pathotypes.

${ }^{\mathrm{g}} \mathrm{H}_{\mathrm{SR}}=$ relative Shannon index of diversity computed on pathotypes or genotypes

${ }^{\mathrm{h}} C_{i}=$ complexity (mean number of virulences per isolate).

i Percentage (and number) of virulence pairs in significant LD computed on complete populations. Significance determined by a Fisher's exact test $(P<0.05)$.

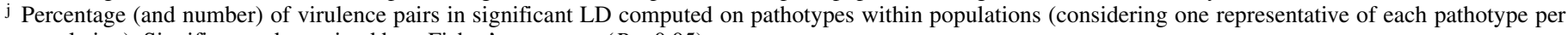
population). Significance determined by a Fisher's exact test $(P<0.05)$.

${ }^{\mathrm{k}} N_{G}=$ number of RAPD genotypes.

${ }^{1} \mathrm{H}=$ Nei's unbiased heterozygosity (31) estimated by the method of Lynch and Milligan (25).

mPercentage of significant linkage disequilibria between RAPD markers. Significance determined by a Fisher's exact test $(P<0.05)$. 
rusts $(1,15,20)$. The Shannon index (26) describes the richness in pathotypes and is calculated as $\mathrm{H}_{\mathrm{S}}=-\Sigma p_{i} \ln p_{i}$, where $p_{i}$ is the frequency of the $i$ th pathotype in the population. Because $\mathrm{H}_{\mathrm{S}}$ is relatively sensitive to the population size $(1,35)$, a relative Shannon index was calculated as $\mathrm{H}_{\mathrm{SR}}=\mathrm{H}_{\mathrm{S}} / \ln N_{i}(1)$, where $N_{i}$ is the total number of isolates of the population. Complexity $\left(C_{i}\right)$ represents the mean number of virulences per isolate (1) and is estimated by $C_{i}=\Sigma_{i}\left(p_{i} v_{i}\right)$, where $p_{i}$ is the frequency of the $i$ th pathotype and $v_{i}$ the number of virulences of the $i$ th pathotype. We first tested the effect of the compartment (cultivated versus wild) on the pathotype richness and on the complexity of populations, and then the effect of the presence of larch, separately within cultivated and wild stands, by an analysis of variance design using the general linear models procedure in SAS (SAS Institute, Cary, NC). Correspondence analysis (CA) was used to illustrate the differentiation of the populations on the basis of their pathotype frequencies, the first axes showing the greatest variance among all the populations. CA was carried out with ADE-4 software (45). The phenotypic differentiation index, sometimes referred to as "Rogers index" (41), differentiates the populations in relation to their pathotype frequencies $(14,15,19)$ : $H_{r}=0.5 \Sigma_{i l}\left|p_{i 1}-p_{i 2}\right|$, where $p_{i 1}$ and $p_{i 2}$ are the frequencies of the $i$ th pathotype in the first and the second population, respectively. The statistical significance of pathotype frequency differences was tested with a $G$ test (43) using POPTOOLS 2.5.5 software (G. Hood, Pest Animal CRC, CSIRO, Crace, Australia).

RAPD patterns were scored as presence or absence (indicated by 1 or 0 , respectively) of a band using GelCompar II gel analysis software (Applied Maths, Sint-Martens-Latem, Belgium), and a matrix of RAPD phenotypes was assembled. Because M. laricipopulina urediniospores are dikaryotic and RAPD markers are dominant, unbiased allele frequency estimators were calculated as described by Lynch and Milligan (25). Unbiased heterozygosity and Nei's unbiased genetic distances (31) also were calculated using TFPGA 1.3 software (M. Miller, Tools For Population Genetic Analyses, Utah State University, Logan).

Linkage disequilibria between virulences were calculated as follows: $\mathrm{D}=p(\mathrm{ViVj}) p(\mathrm{AiAj})-p(\mathrm{ViAj}) p(\mathrm{AiVj})$, where $p(\mathrm{ViVj})$ and $p(\mathrm{AiAj})$ represent the frequency at which virulences $\mathrm{i}$ and $\mathrm{j}$ were associated in the same isolate and the frequency at which they both were absent, respectively, and where $p(\mathrm{ViAj})$ and $p(\mathrm{AiVj})$ represent the frequencies of the presence of only one virulence in the isolates. The significance was tested by Fisher's exact tests on 2-by-2 matrices (presence or absence of the virulence) using the FREQ procedure in SAS, applying sequential Bonferroni corrections (39). Linkage disequilibria between pairs of virulences first were computed on complete populations and then on pathotypes within populations (i.e., considering only one representative of each pathotype per population), in order to avoid an overrepresentation of adapted pathotypes following epidemic multiplication (28). The nonrandom association between RAPD markers also was tested by Fisher's exact tests.

In order to assess the amount of clonality within the most frequent pathotypes, we estimated heterozygosity $(\mathrm{H})$, RAPD phenotypic richness (relative Shannon index of diversity, $\mathrm{H}_{\mathrm{SR}}$ ), and percentage of significant linkage disequilibria within pathotypes that composed more than $20 \%$ of each population.

Genetic and pathotypic structure were assessed using an analysis of molecular variance (AMOVA) (10), based on the Euclidean distance matrix between all pairs of RAPD multilocus phenotypes. Two nested AMOVAs were performed to partition the variance in RAPD phenotype and virulence frequencies among the two compartments (cultivated versus wild), among populations within compartments, and within populations. The computed $\Phi$ statistics are analogous to Wright's $F$ statistics (10). The significance of variance component estimates was tested by 1,000 random permutations. AMOVA analyses were conducted on R. J. Dyer's server (Virginia Commonwealth University, VA). Two
Mantel tests were performed using TFPGA software: the correlation between the matrices of genetic and log-transformed geographical distances was tested to detect isolation by distance, and the correlation between the matrices of pathotypic (Rogers index) and genetic distances also was tested.

\section{RESULTS}

Pathotypic and neutral diversity. In all, 30 different pathotypes were detected in the 13 populations of M. larici-populina, 26 in the populations collected on poplar in September 2001 and 22 in the populations collected on larch in May 2002. Cultivated stands harbored many more pathotypes (12 to 18$)$, which also often were more complex, than did the wild stands (2 to 8 pathotypes) (Table 2), where the null pathotype (with no specific virulence) represented 60 to $85 \%$ of the isolates (Table 3). Among these wild stands, only the population of La Rochette presented a high percentage of complex pathotypes, with $26 \%$ of pathotype 1-3-4-5-7 and 5\% of pathotype 1-3-5-7 (Table 3). Similar patterns of pathotype number and complexity distribution among wild and cultivated stands were observed in the populations collected on larch (Table 2). Four additional pathotypes were detected on larch, two in La Quincy and two in Le Tremblois, one of which possessed the rare and recently described virulence 8 (37) (Table 3). The populations of La Quincy and Champoléon presented a relatively similar pathotypic structure for both collection years; whereas, at Le Tremblois and Siguret, some pathotype frequencies decreased (e.g., 1-3-4-5-7 at Le Tremblois and 0 at Siguret) and others increased (Table 3 ).

Globally, the richness in pathotypes and the complexity of these pathotypes also were significantly higher in the populations from cultivated stands than from wild stands $\left(\mathrm{H}_{\mathrm{SR}}: F_{1,11}=45.64\right.$, $\left.P<0.0001 ; C_{i}: F_{1,11}=132.81, P<0.0001\right)$. In stands with neighboring larch, there was a general but nonsignificant tendency toward higher richness and complexity $\left(\mathrm{H}_{\mathrm{SR}}\right.$ : wild: $F_{1,5}=1.77$, $P=0.241$ and cultivated: $F_{1,5}=1.96, P=0.234 ; C_{i}$ : wild: $F_{1,5}=$ $0.29, P=0.612$ and cultivated: $F_{1,5}=6.36, P=0.065$ ) (Fig. 2 ).

The two compartments also differed in terms of virulence frequencies. In the wild stands, only virulences 2 and 4 were present, and at low frequency, except at La Rochette. The most frequent virulence in the cultivated stands was virulence 4 , which was present in almost $100 \%$ of isolates. The recently described virulence 8 was detected in only one isolate of the population of $\mathrm{La}$ Quincy. Virulence frequencies were very stable over the 2 years of the study (data not shown). Values of the Rogers index (Table 4) were low between populations from the same compartment $(0.07$ to 0.48 ), and high between populations from different compartments (0.68 to 1.00$)$, but the differentiation was highly significant between most populations, even from the same region (e.g., Le Tremblois and St Vallier). The lowest value was obtained for the two wild stands closest to each other, Siguret and Embrun. The two compartments were highly differentiated on the basis of their pathotypic structure. For the four sites with larch, the structure remained relatively stable between populations collected on poplar in September 2001 and on larch in May 2002, except at Siguret, where the differentiation was highly significant (data not shown).

In this study, 19 repeatable polymorphic markers were chosen from the profiles obtained with the three RAPD primers. They were used to determine the multilocus RAPD phenotype of 743 isolates, of which 566 were different. A very high diversity was found in most populations, with almost as many multilocus phenotypes as isolates studied (Table 2). Only the population of La Brillanne exhibited a lower diversity, with only 55 phenotypes among the 91 isolates studied. Accordingly, the values of the relative Shannon index all were higher than 0.9, except at $\mathrm{La}$ Brillanne $\left(\mathrm{H}_{\mathrm{SR}}=0.8\right)$. Within the most frequent pathotypes in each population, the values of $\mathrm{H}_{\mathrm{SR}}$ and $\mathrm{H}$ were similar to those 
computed on the entire populations, except at La Rochette, where both indices showed lowest values within pathotype 1-3-4-5-7, and at La Brillanne, where $\mathrm{H}_{\mathrm{SR}}$ slightly decreased (Table 5).

Linkage disequilibrium. When computed on complete populations, the proportion of virulence pairs in significant linkage disequilibrium was relatively high in populations from cultivated stands (Table 2) and in the populations from the wild stands where complexity (La Rochette) or richness (Champoléon-01) were highest. The virulences that were associated preferentially often were those that composed the complex dominant pathotypes. The sexual stage on larch had different effects on linkage disequilibria in the two compartments: the proportion of significant linkage disequilibria decreased in 2002 in populations from wild stands, whereas it slightly increased or remained the same in populations from cultivated stands. When only one representative of each pathotype per population was considered, only one pair of virulences (virulences 1 and 5) showed significant linkage disequilibria at Le Tremblois (Table 2).

TABLE 3. Numbers of isolates of each pathotype in the Melampsora larici-populina populations collected in September 2001 (Sep) and May 2002 (May) ${ }^{\mathrm{a}}$

\begin{tabular}{|c|c|c|c|c|c|c|c|c|c|c|c|c|c|c|}
\hline \multirow[b]{2}{*}{ Pathotype } & \multirow{2}{*}{$\frac{\text { Blanzy }}{\text { C, Sep }}$} & \multicolumn{2}{|c|}{ La Quincy } & \multirow{2}{*}{$\frac{\text { St Vallier }}{\text { C, Sep }}$} & \multicolumn{2}{|c|}{ Le Tremblois } & \multirow{2}{*}{$\begin{array}{c}\begin{array}{c}\text { La } \\
\text { Rochette }\end{array} \\
\text { W, Sep }\end{array}$} & \multicolumn{2}{|c|}{ Champoléon } & \multirow{2}{*}{$\frac{\text { Embrun }}{\text { W, Sep }}$} & \multicolumn{2}{|c|}{ Siguret } & \multirow{2}{*}{$\begin{array}{c}\begin{array}{c}\text { La } \\
\text { Brillanne }\end{array} \\
\text { W, Sep }\end{array}$} & \multirow[b]{2}{*}{ Total } \\
\hline & & C, Sep & C, May & & C, Sep & C, May & & W, Sep & W, May & & W, Sep & W, May & & \\
\hline 0 & 1 & 0 & 0 & 1 & 0 & 0 & 39 & 68 & 16 & 69 & 64 & 43 & 88 & 389 \\
\hline 1.3 .4 .5 .7 & 32 & 50 & 51 & 24 & 40 & 35 & 17 & 1 & 0 & 0 & 0 & 0 & 0 & 250 \\
\hline 3.4 & 36 & 14 & 12 & 38 & 11 & 16 & 0 & 4 & 1 & 0 & 1 & 2 & 0 & 135 \\
\hline 4 & 3 & 2 & 2 & 10 & 3 & 9 & 3 & 18 & 7 & 21 & 13 & 39 & 0 & 130 \\
\hline 3.4 .7 & 11 & 16 & 19 & 11 & 6 & 14 & 0 & 0 & 0 & 0 & 0 & 0 & 0 & 77 \\
\hline 2 & 0 & 0 & 0 & 1 & 2 & 1 & 2 & 7 & 1 & 10 & 9 & 2 & 16 & 51 \\
\hline 3.4 .5 .7 & 7 & 10 & 7 & 0 & 6 & 16 & 0 & 0 & 0 & 0 & 0 & 0 & 0 & 46 \\
\hline 2.4 & 0 & 1 & 3 & 4 & 18 & 6 & 0 & 1 & 0 & 0 & 2 & 0 & 0 & 35 \\
\hline 1.3 .4 .5 & 5 & 7 & 6 & 4 & 0 & 2 & 0 & 1 & 0 & 0 & 0 & 0 & 0 & 25 \\
\hline 2.3 .4 & 0 & 0 & 0 & 1 & 5 & 3 & 0 & 0 & 0 & 0 & 0 & 0 & 0 & 9 \\
\hline 1.4 .5 & 2 & 0 & 0 & 0 & 5 & 1 & 0 & 0 & 0 & 0 & 0 & 0 & 0 & 8 \\
\hline 3.4 .6 & 2 & 0 & 2 & 1 & 1 & 1 & 0 & 0 & 0 & 0 & 0 & 0 & 0 & 7 \\
\hline 1.3.4.5.6.7 & 1 & 0 & 2 & 0 & 1 & 1 & 0 & 0 & 0 & 0 & 1 & 0 & 0 & 6 \\
\hline 1.3.5.7 & 1 & 0 & 1 & 0 & 1 & 0 & 3 & 0 & 0 & 0 & 0 & 0 & 0 & 6 \\
\hline 4.7 & 0 & 0 & 1 & 2 & 2 & 1 & 0 & 0 & 0 & 0 & 0 & 0 & 0 & 6 \\
\hline 3.4 .5 & 2 & 1 & 0 & 0 & 1 & 1 & 0 & 0 & 0 & 0 & 0 & 0 & 0 & 5 \\
\hline 1.4 .5 .7 & 0 & 1 & 1 & 0 & 1 & 2 & 0 & 0 & 0 & 0 & 0 & 0 & 0 & 5 \\
\hline 3.4 .6 .7 & 0 & 1 & 1 & 0 & 0 & 2 & 0 & 0 & 0 & 0 & 0 & 0 & 0 & 4 \\
\hline 3 & 0 & 1 & 0 & 0 & 0 & 0 & 0 & 1 & 0 & 0 & 0 & 0 & 0 & 2 \\
\hline 1.4 & 0 & 0 & 0 & 0 & 0 & 0 & 1 & 0 & 0 & 0 & 0 & 0 & 0 & 1 \\
\hline 3.7 & 0 & 0 & 0 & 1 & 0 & 0 & 0 & 0 & 0 & 0 & 0 & 0 & 0 & 1 \\
\hline 4.5 .7 & 0 & 0 & 0 & 1 & 0 & 0 & 0 & 0 & 0 & 0 & 0 & 0 & 0 & 1 \\
\hline 1.3 .4 & 0 & 0 & 0 & 0 & 1 & 0 & 0 & 0 & 0 & 0 & 0 & 0 & 0 & 1 \\
\hline 3.4.5.6.7 & 0 & 1 & 0 & 0 & 0 & 0 & 0 & 0 & 0 & 0 & 0 & 0 & 0 & 1 \\
\hline 2.3 .4 .5 .7 & 0 & 0 & 0 & 0 & 1 & 0 & 0 & 0 & 0 & 0 & 0 & 0 & 0 & 1 \\
\hline 1.2 .3 .4 .5 & 0 & 0 & 0 & 0 & 1 & 0 & 0 & 0 & 0 & 0 & 0 & 0 & 0 & 1 \\
\hline 1.2.3.4.5.7 & 0 & 0 & 1 & 0 & 0 & 0 & 0 & 0 & 0 & 0 & 0 & 0 & 0 & 1 \\
\hline 1.3.4.7 & 0 & 0 & 0 & 0 & 0 & 1 & 0 & 0 & 0 & 0 & 0 & 0 & 0 & 1 \\
\hline 1.3.4.5.7.8 & 0 & 0 & 1 & 0 & 0 & 0 & 0 & 0 & 0 & 0 & 0 & 0 & 0 & 1 \\
\hline 1.3.4.5.6 & 0 & 0 & 0 & 0 & 0 & 1 & 0 & 0 & 0 & 0 & 0 & 0 & 0 & 1 \\
\hline Total & 103 & 105 & 110 & 99 & 106 & 113 & 65 & 101 & 25 & 100 & 90 & 86 & 104 & 1,207 \\
\hline
\end{tabular}

${ }^{\mathrm{a}}$ Compartment: $\mathrm{C}=$ cultivated and $\mathrm{W}=$ wild.

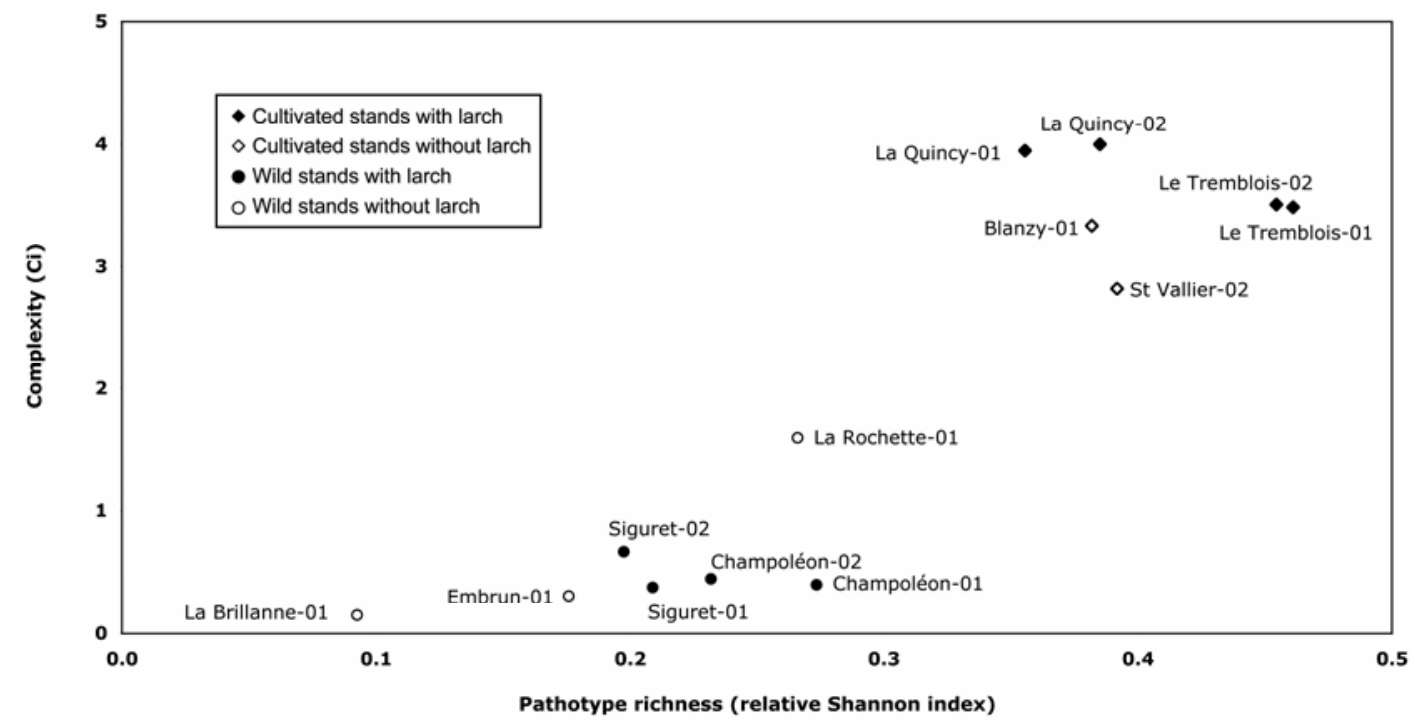

Fig. 2. Complexity (mean number of virulences per isolate) of the 13 Melampsora larici-populina populations plotted against their pathotype richness (relative Shannon index). 
The degrees of linkage disequilibrium between RAPD phenotypes generally were very low, with the greatest linkage disequilibrium at La Rochette, Champoléon, and La Brillanne, three wild stands, and at La Quincy, a cultivated stand (Table 2). Within the most frequent pathotypes, linkage disequilibrium tended to decrease, particularly in the populations cited above (Table 5).

Population structure. The CA performed on pathotype frequencies clearly distinguished both compartments (Fig. 3). The first factorial component, which represented $63 \%$ of the total variance, differentiated populations from the wild and the cultivated stands. The second factorial component $(15 \%$ of the variance) differentiated the populations that showed a peculiar pathotypic structure (e.g., Le Tremblois in 2001, the only population where the pathotype 2-4 was present in high proportion).

The nested AMOVA performed on RAPD markers showed that $90 \%$ of the variation was contained within populations (Table 6). The nine populations of September 2001 were moderately but significantly differentiated, but the "compartment" level explained little of the variation, despite being highly significant. The differentiation between the populations of the two compartments also was relatively low, although significant (Table 6). The analysis performed on virulences showed that the greatest part of the variance was due to intercompartment differentiation, but interpopulation variation also was relatively high (Table 6).

The Mantel test performed on the matrices of Nei's genetic distances and Rogers indices revealed no significant correlation between the pathotypic and molecular structures of the populations $(r=0.077, P=0.294)$. Similarly, the Mantel test performed on the matrices of Nei's genetic distances and log-transformed geographical distances revealed no significant correlation between the molecular structure of the populations and their geography $(r=0.205, P=0.133)$.

\section{DISCUSSION}

The diversity and structure of plant pathogen populations have been studied for many years using virulence markers under strong selection pressure that have allowed the study of a great number of host-pathogen systems, particularly in deeply anthropized ecosystems $(1,19,40)$, as well as in natural ecosystems $(7)$. The aims of this study were to (i) evaluate the differentiation between populations of $M$. larici-populina from wild and cultivated poplar stands and (ii) take into account and evaluate the influence of the presence of the alternate host, larch, in the vicinity of the poplar stands on the population structure of the pathogen.

Although fewer virulences were known at the time, and only virulence markers were used, a previous study of the population structure of $M$. larici-populina on wild and cultivated poplar stands also revealed strong differentiation between the two types of populations (35). Similarly, in this study, the pathotypic structure analysis allowed us to clearly differentiate the populations from cultivated and wild poplar stands. Isolates from cultivated stands frequently had very complex pathotypes (cumulating up to six out of eight known virulences), despite being harvested on a cultivar ('Robusta') with no complete resistance. Complex pathotypes may have been favored in cultivated stands because of their capacity to infect poplar cultivars carrying different complete resistances in the same region of intensive poplar cultivation. The successive selection pressures exerted by the complete resistance genes released seem to have favored the pyramiding of the corresponding virulences within populations of $M$. larici-populina in cultivated stands, giving rise to increasingly complex pathotypes (36). This has been reported in other pathosystems (for instance, in wheat stem rust populations) (40).

Another nonexclusive explanation for the high proportion of complex pathotypes in cultivated poplar stands is hitchhiking,

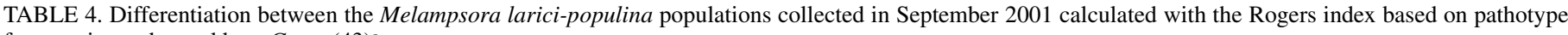
frequencies and tested by a $G$ test $(43)^{\mathrm{a}}$

\begin{tabular}{|c|c|c|c|c|c|c|c|c|}
\hline & La Quincy & St Vallier & Le Tremblois & La Rochette & Champoléon & Embrun & Siguret & La Brillanne \\
\hline Blanzy & $0.30 \mathrm{NS}$ & $0.21 *$ & $0.39 * * * *$ & $0.69 * * * *$ & $0.90 * * * *$ & $0.96 * * * *$ & $0.94 * * * *$ & $0.99 * * * *$ \\
\hline La Quincy & $\ldots$ & $0.44 * * *$ & $0.36 * * *$ & $0.72 * * * *$ & $0.90 * * * *$ & $0.98 * * * *$ & $0.96 * * * *$ & $1.00 * * * *$ \\
\hline St Vallier & $\ldots$ & $\ldots$ & $0.48 * * * *$ & $0.69 * * * *$ & $0.81 * * * *$ & $0.88 * * * *$ & $0.85 * * * *$ & $0.98 * * * *$ \\
\hline Le Tremblois & $\ldots$ & $\ldots$ & $\ldots$ & $0.68 * * * *$ & $0.89 * * * *$ & $0.95 * * * *$ & $0.91 * * * *$ & $0.98 * * * *$ \\
\hline La Rochette & $\ldots$ & $\ldots$ & $\ldots$ & $\ldots$ & $0.31 * * * *$ & $0.32 * * * *$ & $0.32 * * * *$ & $0.37 * * * *$ \\
\hline Champoléon & $\ldots$ & $\ldots$ & $\ldots$ & $\ldots$ & $\ldots$ & $0.08 \mathrm{NS}$ & $0.09 \mathrm{NS}$ & $0.26^{* * * * *}$ \\
\hline Embrun & $\ldots$ & $\ldots$ & $\ldots$ & $\ldots$ & $\ldots$ & $\ldots$ & $0.07 \mathrm{NS}$ & $0.21 * * * *$ \\
\hline Siguret & $\ldots$ & $\ldots$ & $\ldots$ & $\ldots$ & $\ldots$ & $\ldots$ & $\ldots$ & $0.19 * * *$ \\
\hline
\end{tabular}

a NS = nonsignificant; $* * * *$, and $* * * *=$ significance at $P<0.05,0.001$, and 0.0001 , respectively.

TABLE 5. Genotypic and genetic diversity within the main pathotypes of each population of Melampsora larici-populina collected on poplar in September 2001

\begin{tabular}{|c|c|c|c|c|c|c|c|}
\hline Locality & Main pathotypes & Frequency $(\%)^{\mathrm{a}}$ & $N_{i}^{\mathrm{b}}$ & $N_{G}^{\mathrm{c}}$ & $\mathrm{H}_{\mathrm{SR}}{ }^{\mathrm{d}}$ & $\mathrm{H}^{\mathrm{e}}$ & $\operatorname{LD}(\%)^{\mathrm{f}}$ \\
\hline \multirow[t]{2}{*}{ Blanzy } & 1.3.4.5.7 & 31.1 & 30 & 30 & 1.00 & 0.37 & 0.7 \\
\hline & 3.4 & 35.0 & 34 & 31 & 0.96 & 0.35 & 2.5 \\
\hline La Quincy & 1.3.4.5.7 & 47.6 & 48 & 46 & 0.98 & 0.37 & 0.7 \\
\hline \multirow[t]{2}{*}{ St Vallier } & 1.3.4.5.7 & 24.2 & 22 & 21 & 0.98 & 0.28 & 1.1 \\
\hline & 3.4 & 38.4 & 32 & 30 & 0.98 & 0.32 & 1.9 \\
\hline Le Tremblois & 1.3.4.5.7 & 37.7 & 34 & 33 & 0.99 & 0.33 & 1.0 \\
\hline \multirow[t]{2}{*}{ La Rochette } & 0 & 60.0 & 28 & 24 & 0.92 & 0.34 & 1.0 \\
\hline & 1.3.4.5.7 & 26.2 & 15 & 12 & 0.89 & 0.25 & 0.0 \\
\hline Champoléon & 0 & 67.3 & 34 & 34 & 1.00 & 0.35 & 2.2 \\
\hline \multirow[t]{2}{*}{ Embrun } & 0 & 69.0 & 57 & 55 & 0.99 & 0.35 & 1.3 \\
\hline & 4 & 21.0 & 20 & 20 & 1.00 & 0.33 & 0.8 \\
\hline Siguret & 0 & 71.1 & 51 & 50 & 0.99 & 0.37 & 2.0 \\
\hline La Brillanne & 0 & 84.6 & 78 & 44 & 0.77 & 0.28 & 3.7 \\
\hline
\end{tabular}

${ }^{a}$ Frequency of the main pathotypes (>20\%) within each population.

${ }^{\mathrm{b}} N_{i}=$ number of isolates analyzed with random amplified polymorphic DNA (RAPD) markers.

${ }^{\mathrm{c}} N_{G}=$ number of RAPD genotypes.

${ }^{\mathrm{d}} \mathrm{H}_{\mathrm{SR}}=$ relative Shannon index of genotype diversity.

e $\mathrm{H}=$ Nei's unbiased heterozygosity (31) estimated by the method of Lynch and Milligan (25).

f Percentage of significant linkage disequilibria (LD) between RAPD markers. Significance determined by a Fisher's exact test $(P<0.05)$. 
which can occur if several avirulence or virulence loci are tightly physically linked. This type of hitchhiking phenomenon can yield complex pathotypes even if unnecessary virulences are costly, although complexity probably still would be lost in the long term. For example, virulence 7 is widely present within cultivated stands due to the massive plantation during the last decade of $P . \times$ interamericana 'Beaupré' carrying resistance R7 (36). This virulence never was detected alone in the populations studied, always being associated with several other virulences (e.g., pathotype 1-3-4-5-7) (37). Virulence 8 was detected in a single isolate in the present study, probably because of the very recent commercial release of the cvs. Hoogvorst and Hazendans, and also was associated with the same other virulences (pathotype 13-4-5-7-8).

This pyramiding of virulences raises the question of the cost of unnecessary virulences in the Populus-Melampsora pathosystem. Although the low diversity and complexity of pathotypes and the predominance of the null pathotype on wild poplar seem to show that a cost of unnecessary virulences may exist, the increased complexity, including unnecessary virulences, observed over more than 15 years in the cultivated stands does not support this hypothesis (36). Further experiments are needed to test the hy-

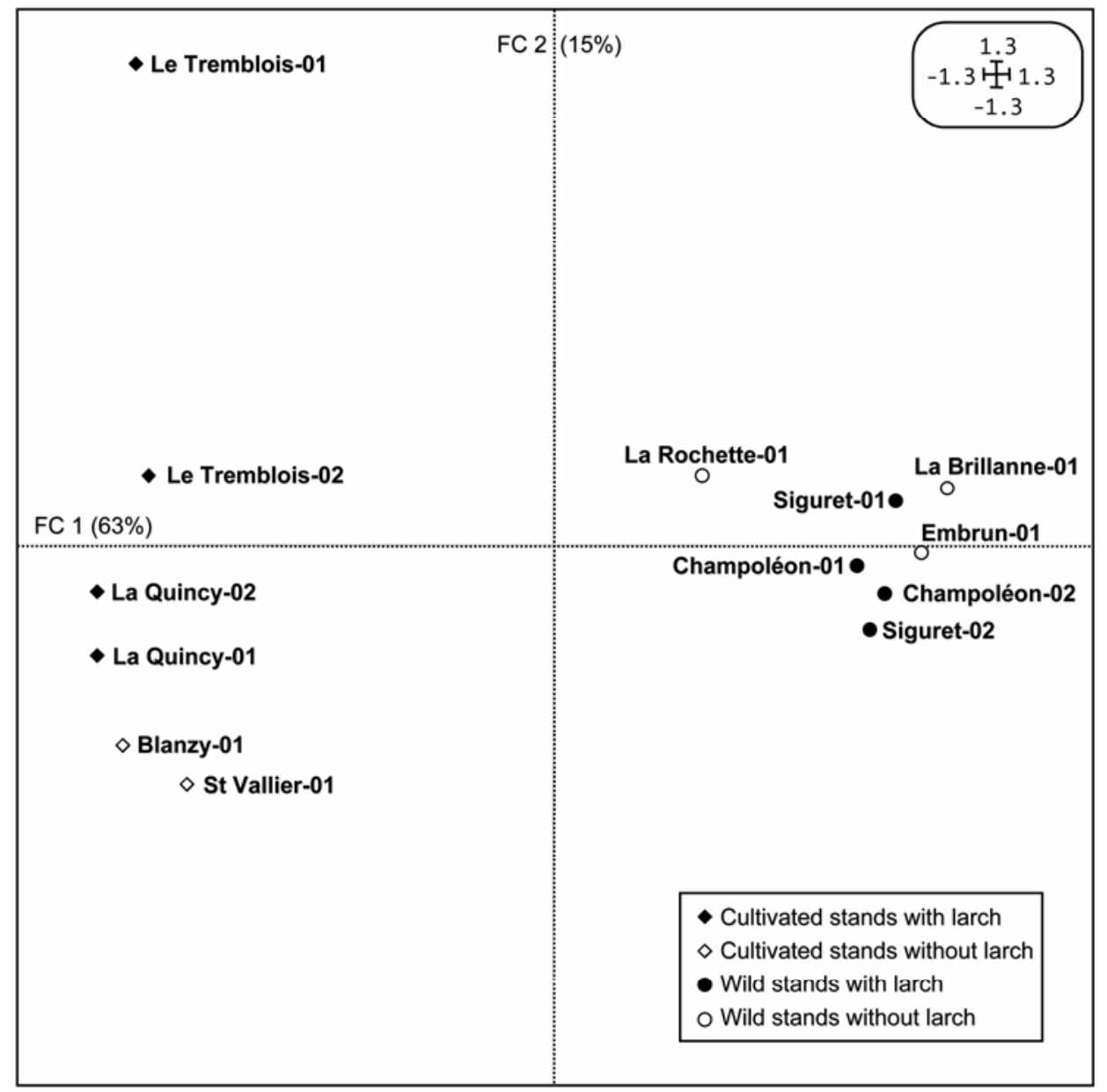

Fig. 3. Results of the correspondence analysis carried out on the pathotype frequencies in the 13 Melampsora larici-populina populations studied. Populations are plotted on the first two factorial components (FC1 and FC2).

TABLE 6. Nested analysis of molecular variance performed on the nine populations of Melampsora larici-populina collected from poplar in September 2001

\begin{tabular}{|c|c|c|c|c|c|}
\hline & $\mathrm{df}^{\mathrm{a}}$ & Variance components & Percent ${ }^{\mathrm{b}}$ & $P$ value ${ }^{c}$ & $\Phi$ Statistics ${ }^{\mathrm{d}}$ \\
\hline \multicolumn{6}{|l|}{ RAPD $^{e}$} \\
\hline Among compartments & 1 & 0.15 & 4.7 & $<0.0001$ & $\Phi_{\mathrm{CT}}=0.047$ \\
\hline Among populations within compartments & 7 & 0.27 & 8.5 & $<0.0001$ & $\Phi_{\mathrm{SC}}=0.092$ \\
\hline Total & 742 & 3.19 & 100.0 & $\ldots$ & ... \\
\hline \multicolumn{6}{|l|}{ Virulences } \\
\hline Among compartments & 1 & 0.92 & 55.4 & $<0.0001$ & $\Phi_{\mathrm{CT}}=0.554$ \\
\hline Among populations within compartments & 7 & 0.07 & 4.2 & $<0.0001$ & $\Phi_{\mathrm{SC}}=0.095$ \\
\hline
\end{tabular}

${ }^{a}$ Degrees of freedom (df).

${ }^{\mathrm{b}}$ Percentage of total variation.

${ }^{c} P$ value obtained by 1,000 randomizations of the data set.

d $\Phi$ Statistics as defined by Excoffier et al. (10).

e RAPD = random amplified polymorphic DNA. 
pothesis of a cost of unnecessary virulences. The question of whether or not the virulence is dominant or recessive is also an important one. If recessive, as predicted by the gene-for-gene relationship and observed in many pathosystems, selection against the unnecessary alleles would take longer. However, from a practical point of view, the accumulation of virulences observed in the cultivated poplar stands probably will render the development of durable resistance difficult in the future $(9,18,30,36)$.

In contrast to cultivated stands, isolates from wild stands had few virulences and low complexity. Similar observations have been reported in populations of $M$. lini, where the virulences found in cultivated stands of Linum marginale were quasi-absent in wild flax populations (21). There may be unknown specific virulences in wild stands; however, because no complete resistance has been found so far in P. nigra (36), it appears more likely that quantitative resistance mechanisms have been selected in the wild pathosystem rather than gene-for-gene interactions. This study also shows that the degree of pollution of the wild poplar stands with complex pathotypes which have been selected by the cultivated stands is very low. Although gene flow between both compartments exists $\left(\Phi_{\mathrm{CT}}=0.047\right)$ (Table 6), the frequency of complex pathotypes (such as 1-3-4-5-7) in the wild stands remains very low. Only the population of La Rochette showed a significant proportion of complex pathotypes, which may be due to the presence of a small plantation of 25 trees of $P . \times$ interamericana 'Beaupré' in its vicinity.

If variation in virulence frequencies was important among compartments $\left(\Phi_{\mathrm{CT}}=0.554\right)$ (Table 6$)$, genetic patterns based on neutral RAPD markers did not clearly differentiate the populations from wild versus cultivated stands. Indeed, the intrapopulation allelic diversity was very high and the differentiation between populations, although highly significant, was quite low $\left(\Phi_{\mathrm{ST}}=0.101\right)$ (Table 6). Similar levels of diversity and differentiation were obtained among populations of M. larici-populina collected from three experimental poplar nurseries across France in another study (11). The AMOVAs showed most molecular variation to be within populations. Moreover, genetic distances between populations were very low and did not comply with geographical distances or with compartment. Hence, the clonal structure of cultivated poplar stands did not seem to influence the neutral genetic structure of $M$. larici-populina populations, which also was shown by the low amount of clonality within the most frequent complex pathotypes in cultivated stands. The lack of correlation between the pathotypic and neutral (RAPD) population structure and the lack of isolation by distance both suggest long-distance dispersal and panmixia among fungal populations from distant regions and from wild and cultivated hosts, associated with strong selection pressures on virulences only in the cultivated stands. It is possible that a larger geographical scale would be necessary to detect isolation by distance similar to that found across the North American continent for Cronartium ribicola populations (16). Furthermore, the discrepancy between the pathotype and neutral population structures may result from the difference in the rate of evolution of virulence markers versus neutral markers. Virulence markers have been shown to evolve very rapidly in the cultivated stands during the past 30 years (36), whereas nothing is known about the rate of evolution of neutral markers in M. larici-populina.

The second aim of this study was to evaluate the effect of the presence of larch, the alternate host, in the vicinity of poplar stands. In this study, the pathotypic and genetic composition of populations sampled in autumn on poplar stands with and without larch from the same region generally was very similar, and the proximity of larch did not seem to have a major effect on the pathotypic and genetic diversity and on the pathotype complexity of the populations. There was only a general but nonsignificant trend toward higher pathotypic richness in the stands with neighboring larch. In a 3-year study of $51 \mathrm{M}$. larici-populina popula- tions, including some collected at the beginning of the epidemics, this trend was confirmed and the effect of larch became significant (12).

When comparing populations collected from poplar trees with or without larch in their vicinity, the presence of the sexual host did not reduce the linkage disequilibria between virulence pairs. However, linkage disequilibria were higher in populations collected from poplar in the wild stands than in populations collected from larch trees at the same sites. Neutral markers also did not reveal any effect of the proximity of larch in the populations collected on poplar in September 2001. Globally, the proportions of pairs of neutral markers in significant linkage disequilibria were low, and the presence of larch in the vicinity of the poplar stands did not further reduce the value of these disequilibria. For example, the population of La Quincy showed one of the highest values of linkage disequilibria, despite the presence of larch in its vicinity, similar to findings for the willow rust fungus, $M$. lariciepitea (42).

The high proportions of virulence pairs in significant linkage disequilibria may reflect strong selection of well-adapted complex pathotypes where virulences are preferentially associated, reducing the diversity in pathotypes available. This selective amplification of some pathotypes is supported by the very low proportions of linkage disequilibrium when considering a single representative of each pathotype. Moreover, clonality seemed to be low within the most frequent pathotypes, as shown by the values of $\mathrm{H}$, $\mathrm{H}_{\mathrm{SR}}$, and linkage disequilibrium for RAPD markers (Table 5). If poplar trees become infected by a pool of sexual products from local larch trees, they also may become infected by aecidiospores from more distant larch populations, with the same pathotypes but genetically different.

It also is worth noting that (i) the local genetic differentiation between different most frequent pathotypes was two- to fourfold higher than between populations from the same regions (data not shown) and (ii) linkage disequilibria usually decreased when considering the most frequent pathotypes relative to the entire population (for example, at La Rochette). These results suggest that reproduction may occur between isolates with the same pathotype, and also support the hypothesis of long-distance dispersal.

There were few novel recombined pathotypes found on larch at the same sites in the following spring. Furthermore, the proportions of virulence pairs in significant linkage disequilibrium was not always lower in populations collected immediately after the sexual stage on larch, and was even higher at La Quincy where larch was present. This may be explained by hitchhiking and strong selection pressure by the alternate host. However, we have no knowledge of either the genetic determinism of the interaction between $M$. larici-populina and Larix sp. or the fitness of different pathotypes on the alternate host. If genes influencing infection success on larch are tightly linked with virulence factors on poplar, some particular pathotypes could be selected by selective sweep. Moreover, we ignored the possibility of overwinter survival of urediniospores, both because it has never been observed under controlled conditions (J. Pinon and P. Frey, unpublished data) and because $M$. larici-populina infections in Alpine valleys appear much later in the season downstream on the river than in the poplar-larch sympatry zone upstream on the river (12).

These patterns may reflect the strong selection of isolates during annual epidemics and the high levels of gene flow. Given the long distances of migration of wind-dispersed pathogens (5), it is difficult to detect an effect of the distance to the alternate host at this scale, as was the case at a continental scale for $M$. medusae f. sp. deltoidae (3). Nonetheless, it would be interesting to study the neutral genetic variability in populations at the start of the epidemics (i.e., in June or July) before large-scale dispersal occurs.

The fungal population of La Brillanne had particularly low pathotypic and genetic diversity and a high proportion of neutral 
markers in significant linkage disequilibrium that may result from a population bottleneck at the end of the migration along the Durance River Valley, as well as the clonal amplification of a few isolates. Indeed, the M. larici-populina epidemic should have started late in the season because only the youngest poplar leaves were infected by M. larici-populina in September 2001, the oldest leaves having been infected earlier by M. allii-populina (P. Frey and C. Husson, unpublished data). Therefore, the Alpine valleys may constitute a good model for studying the population dynamics of M. larici-populina at a local scale, given that larch is present only at high elevations where rust epidemics originate every year.

This study provides new insights into the population biology of M. larici-populina. Gene flow seems to occur over large distances, which certainly plays a major role in the adaptation of the pathogen. In particular, this long-distance dispersal seems to buffer the influence of the presence of the alternate host near poplar stands. Virulence factors that are strongly selected in cultivated poplar stands seem to be unimportant in the adaptation of the rust agent in wild ecosystems. Further studies on more local or larger scales (e.g., continental) and over a longer period of time may provide additional insights into the biology of $M$. laricipopulina. However, the limitations of the use of dominant RAPD markers with a dicaryotic fungus prompted the search for codominant markers. Fifteen microsatellite markers recently were developed for $M$. larici-populina (2). These markers, codominant and amenable to automatization, will render further studies on population genetics of the Populus-Melampsora pathosystem easier.

\section{ACKNOWLEDGMENTS}

Financial support was provided by GIP-Ecofor and INRA. We thank A. Schipfer for technical assistance; P. Munnier, T. Deville, and P. Adami for the choice of the cultivated poplar stands; C. Camy and R. J. Dyer for their help in statistical analysis; J. A. Shykoff and T. Giraud for their great help with earlier versions of the manuscript; and three anonymous reviewers for their helpful comments.

\section{LITERATURE CITED}

1. Andrivon, D., and de Vallavieille-Pope, C. 1995. Race diversity and complexity in selected populations of fungal biotrophic pathogens of cereals. Phytopathology 85:897-905.

2. Barrès, B., Dutech, C., Andrieux, A., Caron, H., Pinon, J., and Frey, P. 2006. Isolation and characterization of 15 microsatellite loci in the poplar rust fungus, Melampsora larici-populina, and cross-amplification in related species. Mol. Ecol. Notes 6:60-64.

3. Bourassa, M., Bernier, L., Milligan, B. G., and Hamelin, R. C. 1998. Sympatry between alternate hosts affects population structure of poplar leaf rust. Pages 65-69 in: Proc. First IUFRO Rusts of Forest Trees Conf. Saariselkä, Finland. R. Jalkanen, P. E. Crane, J. A. Walla, and T. Aalto, eds. Finn. For. Res. Inst. Res. Pap. 712.

4. Brown, J. K. M. 1999. The evolution of sex and recombination in fungi. Pages 73-95 in: Structure and dynamics of fungal populations. J. J. Worrall, ed. Kluwer Academic Publishers, Dordrecht, The Netherlands.

5. Brown, J. K. M., and Hovmøller, M. S. 2002. Aerial dispersal of pathogens on the global and continental scales and its impact on plant disease. Science 297:537-541.

6. Brygoo, Y., Caffier, V., Carlier, J., Fabre, J. V., Fernandez, D., Giraud, T., Mourichon, X., Neema, C., Notteghem, J. L., Pope, C., Tharreau, D., and Lebrun, M. H. 1998. Reproduction and population structure in phytopathogenic fungi. Pages 133-148 in: Molecular Variability of Fungal Pathogens. P. D. Bridge, Y. Couteaudier, and J. M. Clarkson, eds. CAB International, Wallingford, UK.

7. Burdon, J. J. 1993. The structure of pathogen populations in natural plant communities. Annu. Rev. Phytopathol. 31:305-323.

8. Burdon, J. J., Thrall, P. H., and Brown, A. H. D. 1999. Resistance and virulence structure in two Linum marginale-Melampsora lini host-pathogen metapopulations with different mating systems. Evolution 53:704716.

9. Dowkiw, A., Husson, C., Frey, P., Pinon, J., and Bastien, C. 2003. Partial resistance to Melampsora larici-populina leaf rust in hybrid poplars:
Genetic variability in inoculated excised leaf disk bioassay and relationship with complete resistance. Phytopathology 93:421-427.

10. Excoffier, L., Smouse, P. E., and Quattro, J. M. 1992. Analysis of molecular variance inferred from metric distances among DNA haplotypes: Application to human mitochondrial DNA restriction data. Genetics 131:479-491.

11. Feau, N. 2000. Variabilité phénotypique et diversité génétique de trois populations de Melampsora larici-populina Kleb., agent de la rouille des peupliers. Forest Biology M.S. thesis, University of Nancy, France.

12. Frey, P., Gérard, P., Feau, N., Husson, C., and Pinon, J. 2005. Variability and population biology of Melampsora rusts on poplars. Pages 63-72 in: Rust Diseases of Willow and Poplar. M. H. Pei and A. R. McCracken, eds. $\mathrm{CAB}$ International, Wallingford, UK.

13. Gilbert, G. S. 2002. Evolutionary ecology of plant diseases in natural ecosystems. Annu. Rev. Phytopathol. 40:13-43.

14. Groth, J. V., McCain, J. W., and Roelfs, A. P. 1995. Virulence and isozyme diversity of sexual versus asexual collections of Uromyces appendiculatus (bean rust fungus). Heredity 75:234-242.

15. Groth, J. V., and Roelfs, A. P. 1987. The concept and measurement of phenotypic diversity in Puccinia graminis on wheat. Phytopathology 77:1395-1399.

16. Hamelin, R. C., Hunt, R. S., Geils, B. W., Jensen, G. D., Jacobi, V., and Lecours, N. 2000. Barrier to gene flow between eastern and western populations of Cronartium ribicola in North America. Phytopathology 90:1073-1078

17. Hovmøller, M. S., Justesen, A. F., and Brown, J. K. M. 2002. Clonality and long-distance migration of Puccinia striiformis f. sp. tritici in northwest Europe. Plant Pathol. 51:24-32.

18. Jorge, V., Dowkiw, A., Faivre-Rampant, P., and Bastien, C. 2005. Genetic architecture of qualitative and quantitative Melampsora larici-populina leaf rust resistance in hybrid poplar: Genetic mapping and QTL detection. New Phytol. 167:113-127.

19. Kolmer, J. A. 1991. Phenotypic diversity in two populations of Puccinia recondita f. sp. tritici in Canada during 1931-1987. Phytopathology 81:311-315.

20. Kolmer, J. A. 1999. Virulence dynamics, phenotypic diversity, and virulence complexity in two populations of Puccinia triticina in Canada from 1987 to 1997. Can. J. Bot. 77:333-338.

21. Lawrence, G. J., and Burdon, J. J. 1989. Flax rust from Linum marginale: variation in a natural host-pathogen interaction. Can. J. Bot. 67:31923198.

22. Lefèvre, F., Goué-Mourier, M.-C., Faivre-Rampant, P., and Villar, M. 1998. A single gene cluster controls incompatibility and partial resistance to various Melampsora larici-populina races in hybrid poplars. Phytopathology 88:156-163.

23. Legionnet, A., Muranty, H., and Lefèvre, F. 1999. Genetic variation of the riparian pioneer tree species Populus nigra. II. Variation in susceptibility to the foliar rust Melampsora larici-populina. Heredity 82:318327.

24. Lemaire, H., Maugard, F., and Merzeau, D. 1998. Faut-il traiter les peupliers contre la rouille? Essais de traitements sur Luisa Avanzo en Aquitaine. Forêt-Entreprise 121:54-59.

25. Lynch, M., and Milligan, B. G. 1994. Analysis of population genetic structure with RAPD markers. Mol. Ecol. 3:91-99.

26. Magurran, A. E. 1988. Ecological Diversity and Its Measurement. Princeton University Press. Princeton, NJ.

27. McDonald, B. A., and Linde, C. 2002. Pathogen population genetics, evolutionary potential, and durable resistance. Annu. Rev. Phytopathol. 40:349-379.

28. Milgroom, M. G. 1996. Recombination and the multilocus structure of fungal populations. Annu. Rev. Phytopathol. 34:457-477.

29. Miot, S., Frey, P., and Pinon, J. 1999. Varietal mixture of poplar clones: effects on infection by Melampsora larici-populina and on plant growth. Eur. J. For. Pathol. 29:411-423.

30. Mundt, C. C. 2002. Use of multiline cultivars and cultivar mixtures for disease management. Annu. Rev. Phytopathol. 40:381-410.

31. Nei, M. 1978. Estimation of average heterozygosity and genetic distance from a small number of individuals. Genetics 89:583-590.

32. Oates, J. D., Burdon, J. J., and Brouwer, J. B. 1983. Interactions between Avena and Puccinia species. II. The pathogens: Puccinia coronata Cda and P. graminis Pers. f. sp. avenae Eriks. and Henn. J. Appl. Ecol. 20:585596.

33. Peck, J. R., and Waxman, D. 2000. What's wrong with a little sex? J. Evol. Biol. 13:63-69.

34. Pei, M. H., Whelan, M. J., Halford, N. G., and Royle, D. J. 1997. Distinction between stem- and leaf-infecting forms of Melampsora rust on Salix viminalis using RAPD markers. Mycol. Res. 101:7-10.

35. Pinon, J., and Frey, P. 1997. Structure of Melampsora larici-populina populations on wild and cultivated poplar. Eur. J. Plant Pathol. 103:159173. 
36. Pinon, J., and Frey, P. 2005. Interactions between poplar clones and Melampsora populations and their implications for breeding for durable resistance. Pages 139-154 in: Rust Diseases of Willow and Poplar. M. H. Pei and A. R. McCracken, eds. CAB International, Wallingford, UK.

37. Pinon, J., Frey, P., Husson, C., and Schipfer, A. 1998. Poplar rust (Melampsora larici-populina): The development of E4 pathotypes in France since 1994. Pages 57-64 in: Proc. First IUFRO Rusts of Forest Trees Conf. Saariselkä, Finland. R. Jalkanen, P. E. Crane, J. A. Walla, and T. Aalto, eds. Finn. For. Res. Inst. Res. Pap. 712.

38. Rauch, G., Kalbe, M., and Reusch, T. B. H. 2005. How a complex life cycle can improve a parasite's sex life. J. Evol. Biol. 18:1069-1075.

39. Rice, W. R. 1989. Analysing statistical tables. Evolution 43:223-225.

40. Roelfs, A. P., and Groth, J. V. 1980. A comparison of virulence phenotypes in wheat stem rust populations reproducing sexually and asexually. Phytopathology 70:855-862.

41. Rogers, J. S. 1972. Measures of genetic similarity and genetic distance. Studies in genetics VII. Univ. Texas Publ. 7213:145-153.

42. Samils, B., Stepien, V., Lagercrantz, U., Lascoux, M., and Gullberg, U.
2001. Genetic diversity in relation to sexual and asexual reproduction in populations of Melampsora larici-epitea. Eur. J. Plant Pathol. 107:871881.

43. Sokal, R. R., and Rohlf, F. J. 1995. Biometry: The Principles and Practice of Statistics in Biological Research, 3rd ed. W. H. Freeman and Co., New York.

44. Sujkowski, L. S., Goodwin, S. B., Dyer, A. T., and Fry, W. E. 1994. Increased genotypic diversity via migration and possible occurrence of sexual reproduction of Phytophthora infestans in Poland. Phytopathology 84:201-207.

45. Thioulouse, J., Chessel, D., Dolédec, S., and Olivier, J.-M. 1997. ADE-4: A multivariate analysis and graphical display software. Stat. Comput. 7:75-83.

46. Welsh, J., and McClelland, M. 1990. Fingerprinting genomes using PCR with arbitrary primers. Nucleic Acids Res. 18:7213-7218.

47. Williams, J. G. K., Kubelik, A. R., Livak, K. J., Rafalski, J. A., and Tingey, S. V. 1990. DNA polymorphisms amplified by arbitrary primers are useful as genetic markers. Nucleic Acids Res. 18:6531-6535. 